[Agr. Biol. Chem., Vol. 26, No. 10, p. 655 659, 1962]

\title{
Studies on Production of Nucleic Acid and its Related Compounds by Micro-organisms
}

\author{
Part II. Isolation of Auxotrophs of Bacillus subtilis and Conversion of \\ Adenine to Adenosine by these Strains \\ By Michio Kojıma, Yoshihisa Koaze and Takeshi Hara \\ Research Laboratories, Meiji Seika Kaisha, Ltd., Yokohama \\ Received April 24, 1962
}

\begin{abstract}
Mutants of Bacillus subtilis Marburg capable of synthesizing adenosine from adenine in high yield were described. The mutants of B. subtilis Marburg 160 (tryptophan-dependent, streptomycin-resistant) were isolated via either ultraviolet light irradiation or 2,6-diaminopurine treatment. In experiments with 2,6-cliaminopurine, mutants were obtained in very high frequency. It was found that mutants with purine dependency besides tryptophan requirement and streptomycin resistance, accumulated large amounts of adenosine when grown in a glucose mineral medium containing large amounts of adenine. The parent strain and mutants with amino acids, thiamine or adenine dependency, on the other hand, accumulated only small amounts of adenosine and large amounts of hypoxanthine from adenine.
\end{abstract}

\section{INTRODUCTION}

Microbial production of various metabolites, such as amino acids ${ }^{1)}$ and nucleic acids, has attracted considerable attention in the fermentation inclustry in recent years. The most noteworthy success scored in this field has been achieved with the use of auxotrophic mutants of batceria ${ }^{2 \sim 4)}$.

During the past few years the production of nucleic acids and their component nucleotides or nucleosides has been a subject of intensive studies in Japan ${ }^{5)}$. Adenosine is a starting material for the production of various

1) S. Kinoshita, S. Udaka and M. Shimono, J. Gen. Appl. Microb., 3, 193 (1957)

2) K. Nakayama, S. Kitada and S. Kinoshita, Amino Acids, 2, 105 (1960).

3) H.T. Huang, Appl. Microb., 9, 419 (1961)

4) K. Uchida, A. Kuninaka, H. Yoshino and M. Kibi, This Journal, 25, 804 (1961).

5) A. Kuninaka, J. Ferment. Assoc. Japan, 19, 192 (1961). pharmaceuticals and food additives. For example adenosine mono- and tri-phosphates are used for peripheral vascular diseases, and adenosine- $3^{\prime}, 5^{\prime}$-cyclic phosphate is the activator of liver phosphorylase ${ }^{6)}$. Inosinic acid, which is easily derived from adenosine monophosphate, is used as a seasoning ingredient of food.

The present paper deals with the isolation of auxotrophic mutants of Bacillus subtilis via either ultraviolet light irradiation or 2,6diaminopurine treatment and the formation of adenosine from adenine by growing cells of these auxotrophs.

\section{MATERIALS AND METHODS}

\section{Strain and Mutation.}

Auxotrophic mutants of Bacillus subtilis Marburg 6) T.W. Rall and E.W. Sutherland, J. Biol. Chem., 232, 1065 (1958). 


\section{Table I. Culture Media*}

Mutation studies

\begin{tabular}{ccll} 
Complete medium (CM) & \multicolumn{2}{c}{ Minimal medium (MM) } \\
Meat extract & $10.0 \mathrm{~g}$ & $\mathrm{KH}_{2} \mathrm{PO}_{4}$ & $3.0 \mathrm{~g}$ \\
Polypepton & 10.0 & $\mathrm{~K}_{2} \mathrm{HPO}_{4}$ & 7.0 \\
Yeast extract & 1.0 & $\mathrm{Na}_{3}-$ citrate $\cdot 2 \mathrm{H}_{2} \mathrm{O}$ & 0.5 \\
& & $\left(\mathrm{NH}_{4}\right)_{2} \mathrm{SO}_{4}$ & 1.0 \\
(pH 6.8) & & $\mathrm{MgSO}_{4} \cdot 7 \mathrm{H}_{2} \mathrm{O}$ & 0.2 \\
& & $\mathrm{Glucose}$ & 5.0 \\
& & L-Tryptophan & 0.03
\end{tabular}

Adenosine formation

Preculture medium (StB) Culture medium (KOHMM)

$\begin{array}{lcll}\text { Meat extract } & 4.0 \mathrm{~g} & \mathrm{KH}_{2} \mathrm{PO}_{4} & 8.46 \mathrm{~g} \\ \text { Polypepton } & 10.0 & \mathrm{KOH} & 2.26 \\ \text { Glucose } & 1.0 & \mathrm{Na}_{3}-\text { citrate } \cdot 2 \mathrm{H}_{2} \mathrm{O} & 0.50 \\ \quad(\mathrm{pH} \mathrm{6.6 \sim 7.0)} & & \left(\mathrm{NH}_{4}\right)_{2} \mathrm{SO}_{4} & 1.00 \\ & \mathrm{MgSO}_{4} \cdot 7 \mathrm{H}_{2} \mathrm{O} & 0.20 \\ & \text { In case of solid culture, } & \text { Glucose } & 5.00 \\ 2.0 \% \text { agar was added } & \text { L-Tryptophan } & 0.03 \\ \text { to the medium. } & \text { Adenine } & 0.50 \\ & \text { Other supplements } \\ \text { * per liter. } & & \end{array}$

160* (tryptophan-dependent and streptomycin-resistant) were obtained by either ultraviolet light (UV) irradiation or 2,6-diaminopurine (DAP) treatment, and isolated with the aid of penicillin screening ${ }^{7)}$ and replica methods ${ }^{8)}$. The dose of ultraviolet light irradiation was $90 \mathrm{sec}$ at the distance of $30 \mathrm{~cm}(2080$ $\mathrm{erg} / \mathrm{mm}^{2}$ below $2530 \AA$ ). The procedure for the isolation of auxotrophic mutants by 2,6-diaminopurine is as follows. A spore suspension which had been heat-shocked at $60^{\circ} \mathrm{C}$ for five minutes, was inoculated into $10 \mathrm{ml}$ of the minimal medium (Table I) supplemented with L-tryptophan $(30 \mu \mathrm{g} / \mathrm{ml})$, adenine $(20$ $\mu \mathrm{g} / \mathrm{ml})$ and 2,6-diaminopurine $(500 \mu \mathrm{g} / \mathrm{ml})$. After shaking on a Monod type shaker at $37^{\circ} \mathrm{C}$ until the cell population density reached approximately $10^{8} / \mathrm{ml}$, the cells were centrifuged, washed twice with $0.1 \mathrm{M}$ phosphate buffer ( $\mathrm{pH}$ 7.2) and were resuspended in the complete medium (Table I). The resuspended cells were shake-cultured for $6 \mathrm{hrs}$ at $37^{\circ} \mathrm{C}$. The cells were than harvested by centrifugation, washed twice with the phosphate buffer and inoculated into the minimal medium supplemented with either Ltryptophan or L-tryptophan plus penicillin $(200 \mathrm{u} / \mathrm{ml})$

\footnotetext{
* This strain was kindly supplied by Prof. Y. Ikeda, the Institute of Applied Microbiology, University of Tokyo.

7) B.D. Davis, J. Amer. Chem. Soc., 70, 4267 (1948.

8) J. Lederberg, J. Bact., 63, 399 (1952).
}

for another incubation at $37^{\circ} \mathrm{C}$ with shaking (penicillin screening). When the population density of the L-tryptophan medium reached approximately $10^{8} /$ $\mathrm{ml}$, the cells of the latter culture were centrifuged, washed twice with phosphate buffer to remove penicillin and resuspended in the complete medium. One tenth milliliter aliquots of the cell susepnsions were spread on the surface of the complete agar plates and the plates were incubated for $18 \sim 20 \mathrm{hrs}$ at $37^{\circ} \mathrm{C}$ (master plate). Colonies appeared on master plates were replicated onto both minimal agar plates supplemented with L-tryptophan and complete agar plates with the aid of velvet cloth (replica methods). After incubation for $40 \mathrm{hrs}$ at $37^{\circ} \mathrm{C}$, colonies that appeared on complete agar plates but not on minimal agar plates supplemented with L-tryptophan were isolated.

Nutritional requirements of the colonies obtained above were determined by the inoculation on the minimal agar plates supplemented with L-tryptophan and either casamino acid, mixture of seven kinds of purine and pyrimidine bases or mixture of ten kinds of vitamins. For the determination of specific requirements, paper discs which had previously steeped in a solution of amino acids, purine and pyrimidine bases or vitamins and dried, were placed on the surface of minimal agar plates supplemented with itryptophan after being spread with a washed cell suspension, and after incubation for $24 \mathrm{hrs}$ at $37^{\circ} \mathrm{C}$ the plates were examined for growth.

\section{Screening Experiments for the Formation of Ade- nosine from Adenine.}

Culture of the mutant strains for adenosine production was carried out as follows. Test tubes containing $10 \mathrm{ml}$ of the preculture medium (Table I) were inoculated with the mutant strains grown on slants. After incubation for $6 \sim 7 \mathrm{hrs}$ at $37 \pm 1^{\circ} \mathrm{C}$ with shaking, $0.3 \mathrm{mi}$ portions of these precultures were transferred into $10 \mathrm{ml}$ of the culture medium (Table I) and incubated for $37 \sim 39 \mathrm{hrs}$ with shaking. The cells were removed by centrifugation and the supernatants were examined for adenosine formation by paper chromatography as described previously ${ }^{\ominus)}$.

3. Quantitative Determination of Adenosine, Adenine, Hypoxanthine and Inosine.

Quantitative determination of adenosine, adenine, hypoxanthine and inosine was carried out by arrange-

9) Y. Yamada, K. Ezawa, Y. Koaze and T. Hara, This Journal, 26, 648 (1962). 
ment of paper chromatographic methods ${ }^{10,11)}$ using a developing solvent system previously reported ${ }^{9)}$.

\section{Chemicals.}

2,6-Diaminopurine used as a mutagen was obtained from California Corporation for Biochemical Research. Glucose was obtained from Difco Laboratories and sodium citrate was obtained from Wako Pure Chemical Industries, Ltd. Other chemicals used for mutation studies were obtained from E. Merck AG Darmstadt.

TABLE II. ISOLATION OF AUXOTROPHS OF Bucillus subtilis MARBURG 160

\begin{tabular}{crrrrrr}
\multicolumn{4}{c}{ Number of colonies } \\
$\begin{array}{c}\text { Muta- } \\
\text { gen }\end{array}$ & $\begin{array}{c}\text { Exami- } \\
\text { ned* }\end{array}$ & $\begin{array}{c}\text { Not grown } \\
\text { on MMT }\end{array}$ & $\begin{array}{c}\text { MMT } \\
+ \text { CA }\end{array}$ & $\begin{array}{c}\text { MMT } \\
+\mathrm{V}\end{array}$ & $\begin{array}{c}\text { MMT } \\
+ \text { NA }\end{array}$ \\
UV & 1385 & 51 & 46 & 2 & $3(3) * *$ \\
DAP & 618 & 604 & $-* * *$ & - & $-(5)$
\end{tabular}

MMT : MM supplemented with L-tryptophan $(30 \mu \mathrm{g} / \mathrm{ml})$. MMT+CA : MMT supplemented with easamino acid $(1000 \mu \mathrm{g} / \mathrm{ml})$. MMT +V : MMT supplemented with ten vitamins.

MMT+NA: MMT supplemented with seven purine and pyrimidine bases.

* After penicillin screening.

** Growth response on MMT supplemented with adenine $(30 \mu \mathrm{g} /$ $\mathrm{ml}$ ).

*** Not examined.

\section{RESULTS AND DISCUSSION}

\section{Mutation.}

Results on the isolation of auxotrophic mutants are shown in Table II. With ultraviolet light irradiation only 51 colonies were nutritional mutants out of 1385 colonies appeared on master plates. With 2,6-diaminopurine treatment, however, 604 mutant colonies were obtained out of 618 colonies examined.

In 1959 E. Freeze ${ }^{12}$ ) reported 2,6-diaminopurine as a mutagen for $T_{4}$ phage and it is now known that 2-aminopurine is directry incorporated into DNA in place of adenine to act as a mutagen ${ }^{13,14)}$.

\section{Adenosine Formation from Adenine.}

As shown in Table III and Fig. 1, only tryptophan and purine dependent and streptomycin-resistant strains, for example 160-88, accumulated large amounts of adenosine from adenine. The parent strain and amino acids, thiamine or adenine dependent mutants accumulated large amounts of hypoxanthine but only small amounts of adenosine from ade-

TABle III. Adenosine Formation From ADENINE By B. subtilis MARBURG 160 AND ITS AUXOTROPHS

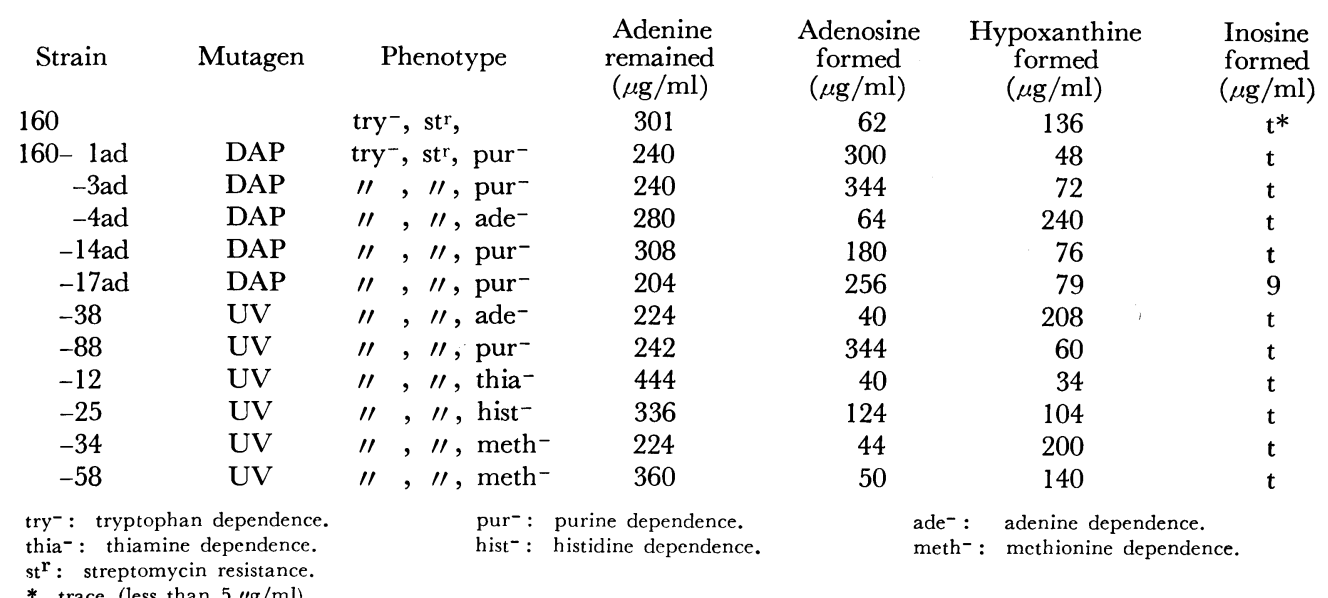

10) G.R. Wyatt, "The Nucleic Acid", Academic Press, 1955, Vol, I, p. 260.

11) A. Bendich, "Methods in Enzymology", Academic Press, 1957, Vol. I, p. 716 .
12) E. Freeze, J. Mol. Biol., 1, 87 (1959).

13) E. Strelzoff, Biochem. Biopys. Res. Comm., 5, 84 (1961).

14) A. Wacker, S. Kirschfeld and L. Trager, J. Mol. Biol., 2, 24 


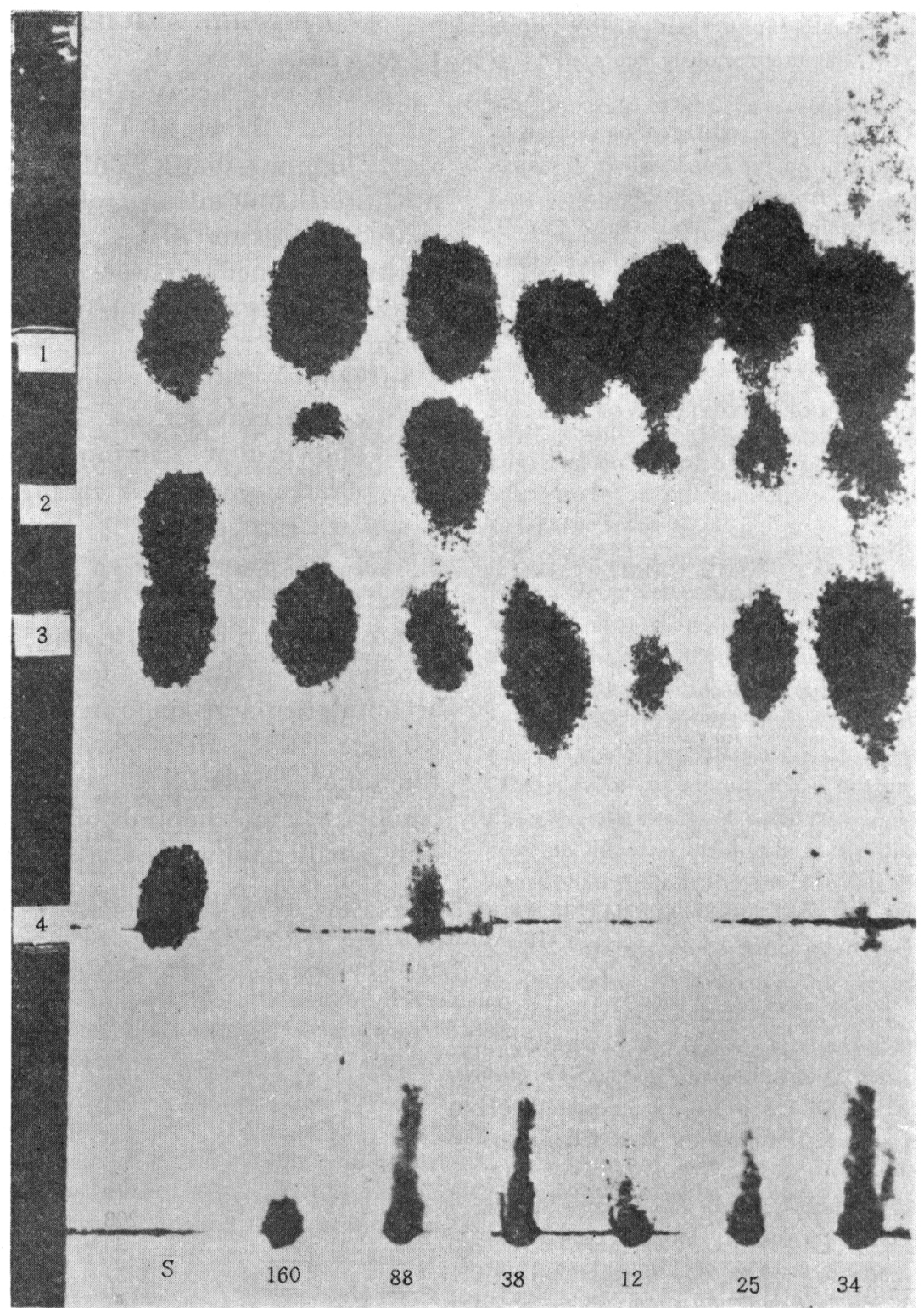

FIG. 1. Paper Chromatogram of Culture Fltrates of B. subtilis Marburg 160 and Its Auxotrophs. Solvent: methylisobutylketone-acetic acid-water $(4: 2.5: 1$, v/v)

$\mathrm{S}$ : $\quad$ authentic compounds: 1 ; adenine, 2; adenosine, 3; hypoxanthine, 4 ; inosine.

nine.

3. Growth Response of $\boldsymbol{B}$. subtilis Marburg $160-88$ on Various Purine and Pyrimidine Compounds. As shown in Fig. 2, all the natural purine compounds examined, i.e. purine bases, their nucleosides and nucleotides supported the growth of this strain, especially bases and nucleosides were well utilized. Unnatural 


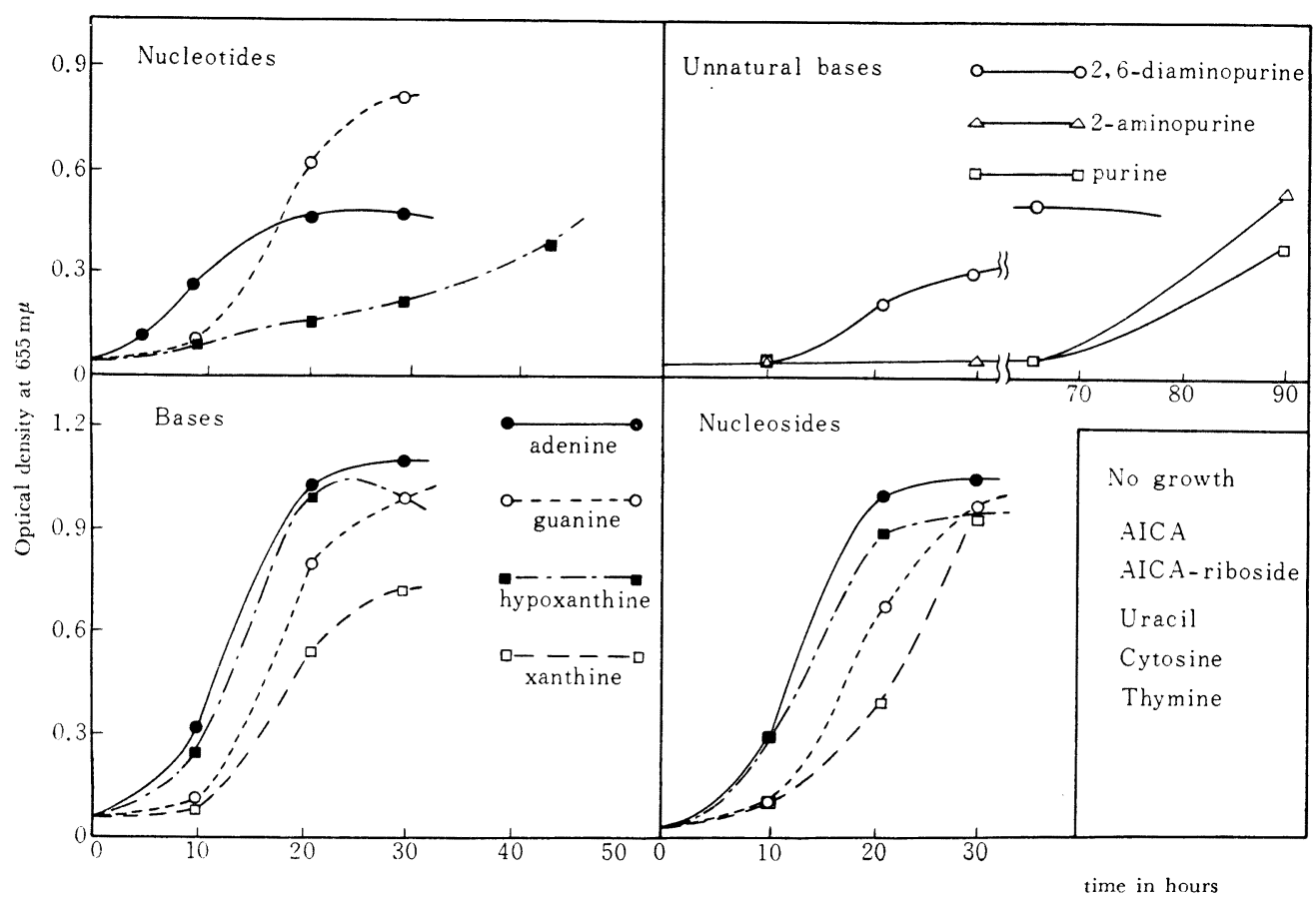

FIG. 2. Growth Response of B. subtilis Marburg 160-88 on Various Nucleic Acid Related Compounds.

Washed cell suspension, cultured in StB medium, was inoculated into KOHMM supplemented with L-tryptophan and the above mentioned compounds $\left(10 \mu \mathrm{g} / \mathrm{ml}\right.$ in base concentrations) and was incubated at $37 \pm 1^{\circ} \mathrm{C}$ with shaking. Growth is shown as change in optical density measured at $655 \mathrm{~m} \mu$.

purine bases such a purine, 2-aminopurine and 2,6-diaminopurine were hardly utilized. Pyrimidine bases, 4-amino,5-imidazole carboxyamide and its riboside could not support the growth of this strain. From these results this strain has been concluded to be a nonexacting purine-less mutant.

Acknowledgement. The authors wish to ex- press their sincere thanks to Prof. Y. Ikeda and Assistant Prof. H. Saito, the Institute of Applied Microbiology, University of Tokyo, for their advice and suggestions. Thanks are also due to members of the Section of Biochemistry of our Research Laboratories for their suggestions and cooperations. 